\title{
Practice of Innovation Education
}

\author{
Hongyan Shi ${ }^{1, a}$, Man Liu ${ }^{2, b}$, Hu Chao ${ }^{3, \mathrm{c}}$ and Lin Jiang ${ }^{4, \mathrm{~d}}$ \\ ${ }^{1,2,4}$ Aerial Ammunition Department,Air Force Logistics College,P.R.China,210000 \\ ${ }^{3}$ Department of Basic Education, Air Force Logistics College, P.R China,210000 \\ Email:ashy7823@163.com
}

Keywords: Innovation education,Humanity hypothesis, Generative teaching.

Abstract. Essentialism thinking under the influence of innovation education adhere to the integrity of human nature hypothesis, this assumption leads to value orientation errors in the practice exploration, such as utilitarian excessively, nationalism, materialistic science, and so on.Innovation education, therefore, the human nature assumption should be initiative exists to generative now.In the generative exists in human's unfinished, finite, historic characteristics and complexity of innovation education practice exploration provides premise, power support, starting point and evaluation dimensions, etc.Innovation education from the education concept to education practice under the influence of the changing needs to go beyond essential thinking instruction in advance.The generative teaching as an important way to innovation education practice rationality.

\section{Introduction}

The dramatic changes in the environment and the increasingly fierce competition for survival, innovation has become a driving force for the development of The Times and ask standing in the way of human fate.In the field of science and technology innovation promotes our country put forward the strategy of developing the country, although the innovation education arises at the historic moment are finding life difficult now.As to the condition of the education, "qian asked" reminds us that it is necessary to adhere to the "people-oriented" value orientation.Recognition by reflecting on human itself, and review the human nature assumption of innovation education and to find more suitable for the innovation education teaching mode, is education innovative development dilemma might be a way out.

\section{Creative education leads to the bias error of value orientation}

Innovation education was put forward on the forward under the guidance of essentialism thinking way, the people of the connotation of innovation education and the image, status, as well as needs understanding on integrity.Now flourish there will be some or certain attributes represent many other attributes as the essence of man, take people as a sort of advance into or ready-made objects of the same, with a fixed and static framework to shape and measure, the pursuit of a lot of specification and order.Nature in the first set, everything "under the statute of people trying to innovation education design a set of precise and controllable and verifiable practice mode.Education subject in such a situation gradually lost the vigor of life and freedom, the person's education into physical education, the rigidity of the education process led to dismembered and materialized, the value orientation errors of innovation education practices lead to loss of innovation education subject.

\section{1 the understanding of creative educational connotation and task errors}

"Innovation education refers to the accordance with the requirements of socialist modernization development of people, have a destination, cultivate the creativity of the teenagers, the innovation ability and innovative personality education."[1] to implement innovation education is the premise of correctly grasp the connotation of innovation, innovation is a relative concept, to individuals, understanding and practice of innovation is relative to its past experience bestow new discoveries, mainly is the human inheritance and regeneration of existing achievement.School education should 
reflect in exploring the innovation education racking their brains to come up with the practice of the so-called "innovation", clear the primary task of innovation education is to cultivate innovation spirit and innovation ability and innovative personality (as shown in table 1).

Table1 Selected the analysis vector for training from database

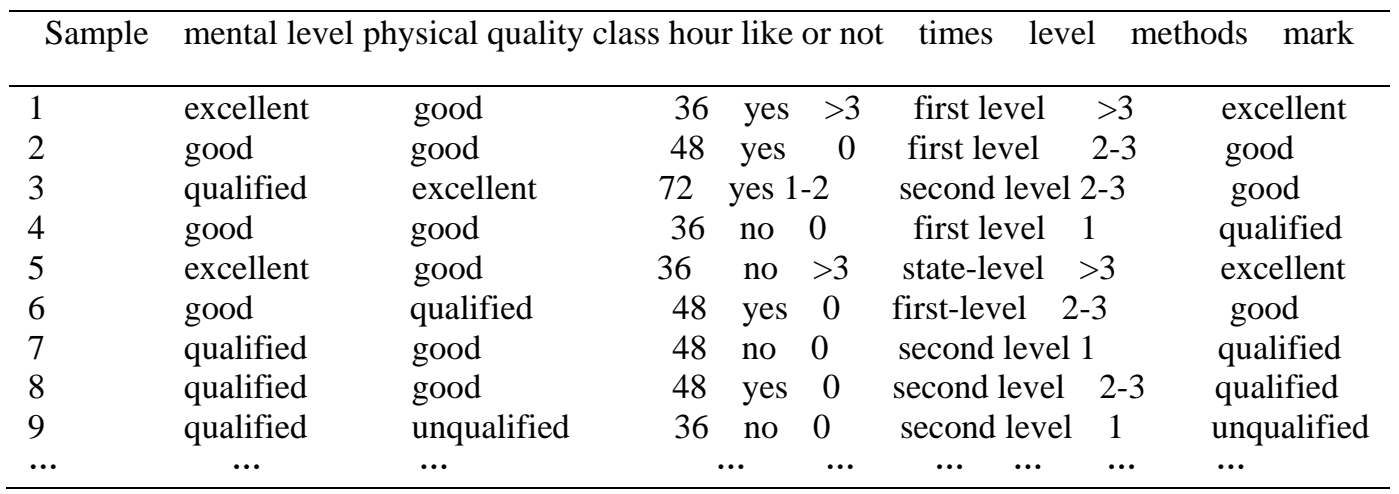

\subsection{The innovation education excessively utilitarian of limbs}

In the innovation education practice, people often only cares about "create what" "how to create" , but neglect "how to create" and "create for who" value judgment.Ethical problems of innovation education activity is rarely touched, flesh and blood of the whole people are living to dismember for utilitarian goal only without the humanistic spirit of "rational man" "robot" "natural person" and so on all sorts of one-sided.Elements left out innovative personality, innovative education with the fear of life, to abandon the experience of life, the harmonious development of human society need the sense of responsibility, sense of mission.

\subsection{The innovation of education only national socialist orientation lead to personal mode}

Education especially emphasizes the freedom of personality and experience, intuition, inspiration of Epiphany innovation education as countries to achieve a certain purpose tool, the country's social character as the running parts, basically is human nature.Not only that, a series of innovative talent training discipline means such as "project" and the evaluation indexes are used to make innovation education by the state power outside to promote the process of concrete process and determine the innovation education, status and results of people's motivation, attitude, value demand is to evade or rejects.

\subsection{The science orientation of innovation education to make it out of people's life}

"Scientific epistemology while also emphasizes the students' initiative in the learning process, but no matter how stressed that it is a kind of external, is nothing more than the" stimulate interest ", "harder" get outside his knowledge, skill, and is not involved in the teaching process, construct their own knowledge." ${ }^{[2]}$ all meaning are simplified for possession of scientific knowledge, rather than on the natural, social, and spiritual experience and practice.Such innovation education forgotten, forgotten life world, lost the meaning of life science, make themselves into blind and invalid position, make the person lost create the life vigor.

\section{The basis of the practice of creative education of generative exist}

E.Cassirer once said: "the human nature is not a substantive things, but of shaping oneself a process: the real human nature is a person of infinite creation activities." ${ }^{[3]}$ in this sense, innovation is a human nature, the awareness of innovation education is the most close to human native education.Innovation education is to make individuals generated in the continual creative practice the fullness of meaning of life, in the free conscious practice make humanity fully unfolded.

\subsection{The unfinished is a prerequisite for innovation education}

Nature gives people choose to do or not do what of freedom, that freedom based on relative to the 
other the lack of animal instinct.Innovation education is to actively cope with all kinds of uncertainty in future.The appearance of its own form will contain the meaning of innovation.Innovation education should be on the premise of people's unfinished and abide by the basic rule of physical and mental development, both stressed that person's subjective initiative, relying on people's own understand feeling to explore the unknown.

\subsection{The limitations of man is the power of innovation education}

"For the conscious existence, existence is the original, original is mature, mature is to create infinite self." ${ }^{[4]}$ innovation for each individual is a state of reality and the behavior inevitably.Unfinished, innovation education should respect people's self choice, powered by people his limitation, to the opportunity to demonstrate their humanity education main body and the stage.Innovation education is to help people's survival motivation into the unknown world, and the new open to individual and collective human understanding and practice space (as shown in table 2).

Table2 The attribute of information gain and rate of information gain

\begin{tabular}{ccc}
\hline Attribute & information gain & rate of information gain \\
\hline Times of students participating & 0.2124 & 0.6251 \\
Level of teacher's technology & 0.2018 & 0.5342 \\
Degree of students' love & 0.1381 & 0.3714 \\
Methods of teacher's teaching & 0.1149 & 0.3361 \\
Class hour & 0.0742 & 0.2912 \\
Level of integrate & 0.0591 & 0.2113 \\
Physical fitness & 0.0326 & 0.1346 \\
\hline
\end{tabular}

\subsection{The historic is the starting point of innovation education}

"The nature of society is not a single person opposite abstract general strength, but the nature of every single person, is the activity of his own and his own life." ${ }^{[5]}$ individuals have to seek development in succession, must constantly innovate in the social environment.Out of the environment, innovation, there is no secure value, don't continue to explore innovative education.

\subsection{The complexity of the people was the home of the innovation education evaluation dimensions.}

People itself is the process of generating dynamic open and complex human complexity far beyond the existing human understanding."Research, found that is in an uncertain and undecidable opening progress."The complexity of ${ }^{[6]}$ people make everyone become a unique, individual, and then make the evaluation is not accurate.Complexity requires evaluation of the innovation education to face the man continuously generate multiple image, the people there was no point trying to fully grasp the innovation education, only via ethics to maintain the good qualities of innovation education middleman, so to evaluate whether the innovation education is beneficial to people's freedom.

\section{The innovation education practice way: generative teaching}

School education is efficient in promoting individual socialization."For books and the symbols of knowledge has been mastered, formal education for young people to gain experience has paved the way, if let young people gain training in informal contact with others, they are not the classics

The test." ${ }^{[7]}$ for social education's first priority is to inherit human culture, prevent degradation society, maintaining social stability. The concept of innovation education is the education of the child, in ought to horizon, innovation education is a kind of education idea, the first is according to the principle of interaction between the life world subjects with an open and transcendental attitude for the future planning, and then is a kind of education practice mode of exploration, in different stages of education focus on different aspects.

Innovation education from education concept to the education practice of formed under the influence of changing needs to go beyond essential thinking instruction, to generative teaching. The teaching aim of generative teaching focus on the person's inner experience and spiritual world of care, the pursuit of value.Fact is a kind of main fact, the so-called value refers to the subject and 
object, the object has attributes was understanding and the influence on the people after using ${ }^{[8]}$.It can be said that human knowledge is value the fact, because it is through unifying of subjectivity.Innovation education is a kind of active facts of education practice, to explore new value in the generative teaching skillfully through the generation of people to achieve reunification of the fact and value, stimulate innovation consciousness, the experience to create beauty, apprehend the meaning of life.

\section{References}

[1] GUO WenAn.Discussion about the innovation education and its characteristics [J]. Chinese journal of education, 2000(1): 9-12.

[2] FENG JianJun.Education and Life[M].BeiJing: Education science press, 2004: 53.

[3] KA XiEr.An Essay On Man[M].GAN Yang, translate.ShangHAI: Shanghai translation publishing press, 1985: 5.

[4] BO GeSen. Evolution Creative [M].WANG LiZhen,YU XiGuang translate.ChangSha:hunan people's publishing house, 1989: 10-11.

[5] The central committee of the communist party of China, Marx and Engels, Lenin Stalin book compilation. Marx Gus corpora[M]. Beijing: people's publishing house,vol 42,1980: 24-25.

[6] Edgar morin. Complexity theory and education problems [M]. Chen YiZhuang translate.. Beijing: Peking University press,2004: 46.

[7] Du Wei. Democracy and education [M], Beijing: people's education Press,2001: 13.

[8] Du Shi zhong. Science and humanities education [M]. Wuhan: central China normal university Press,1998: 139. 